\title{
Borderline Personality Disorder in the Context of Entropy Neuron-Glial Networks of the Brain
}

\author{
Rosman SV* \\ Physician of functional diagnostics of SBIH, Regional psycho neurological clinic, Russia
}

Submission: July 11, 2017; Published: July 24, 2017

*Corresponding author: Rosman SV, Physician of functional diagnostics of SBIH, Regional psycho neurological clinic, Tver, Russian Federation, Russia, Tel: +7-903-800-11-05; Email: seros2005@mail.ru

\begin{abstract}
On the basis of a new unique method - dispersion of amplitude-frequency characteristics of the alpha rhythm, the ability to diagnose widespread among the population borderline personality disorders underlying the deviant behavior of individuals, related addictive disorders, aggressive and auto aggressive actions. The technique allows moving from categorical methods of diagnosis in psychiatry to demensial, to a certain extent, providing the search of a new paradigm.

Abbreviations: BPD: Borderline Personality Disorder; DAFCAR: Dispersion of Amplitude-Frequency Characteristics of the alpha Rhythm EEG; NGNB: Neuron-Glial Network of the Brain; CD al: Coefficient of Dispersion of alpha-Rhythm EEG-1(the quotient of the moral values of power of alpha rhythm to his total power in the range of 7-13 Hz); CD 22: Coefficient of Dispersion of the alpha-Rhythm EEG-2(the quotient of the power of the alpha rhythm in the range of "a modal value $\pm 0.5 \mathrm{~Hz}$ " to his total power in the range of 7-13 Hz); f 01(02): Value of the Modal Frequencies in Occipital Electrodes; f F3(F4): Value of the Modal Frequencies in Frontal Electrodes; $\Delta f$ 01(O2)-F3(F4): Value of the Difference of Modal Frequencies Between the Occipital and Frontal Electrodes; IIDA: Integral Index of Dispersion of the Alpha rhythm EEG(Value of the Kurtosis of the Normal Distribution CD $\alpha$ l in the Occipital Electrodes); ADA: Asymmetry Distribution of the Alpha rhythm EEG (Value of the Asymmetry Distribution $\mathrm{CD \alpha l}$ in the Occipital Electrodes); IIH: Value of the Index Hypofrontality (Kurtosis of the Normal Distribution CD $\alpha$ l in the Frontal Electrodes); AH: Value of the Asymmetry of CD $\alpha$ lin the Frontal Electrodes; CV\% - the Coefficient of Variation; CU: Conditional Unit
\end{abstract}

\section{Introduction}

Edge psychiatry in the modern world is constantly increasing. This is due to several factors.

a) The study of borderline psychiatry allows closer approach to the main task of psychiatry on the modern stage - the search for new paradigms of this discipline, since in this condition begin to show the key differences between normal and pathologically altered mentality.

b) BPD represents a permanent latent threat for both the patient and the people around him, because there is a risk of unpredictable actions on his part with the most disastrous consequences. Do not be an exaggeration if we say that the most resonant crimes of last time: the terrorist attacks, transport accidents, major economic crimes, incidents of mania occurred mainly people suffering from BPD. In addition, these patients represent the bulk of addictive disorders - drug addiction, alcoholism, gambling.

c) BPD patients often have very valuable qualities, and play a significant role in civilization the process of society, so cure them, or at least reducing their suffering would play a significant role in the further evolutionary progress of mankind.
Psychiatrists describe BPD as a serious mental illness characterized by instability in moods, interpersonal relationships, self-esteem and behavior. This instability often interferes with family and work life, long-term planning and orientation in self. Initially believed that in the "borderline" of psychosis, people with BPD suffer from a disorder of the regulation of emotions Less well known than schizophrenia or bipolar dis-the craving (manic-depression), BPD is more common disease affecting 2\% of adults, mostly young women. Among this population there is a high level of self-harm without suicidal intent, as well as a significant rate of suicide attempts and completed suicides in severe cases [1]. Patients often require intensive psychiatric care and $20 \%$ of psychiatric hospitalizations. However, after helping as many of them are improving over time and are eventually able to lead productive lives [2].

In General we can say that BPD is a personality disorder characterized by extreme "black and white" thinking, mood swings, violation of social relationships and difficulty in functioning on a mature level [3]. A special place this disease has in the practice of addictive disorders. Obviously, the majority of drug addicts, alcoholics and gamers began to resort to this method of psycho stimulation in a state of dysphoria, which is the 
leading symptom of BPD. That's why the majority of alcoholics and drug addicts suffer from this disease. In the future, the process begins to develop the script of "vicious circle" - are both diseases mutually aggravate each other.

Despite adequate representation in the psychoanalytic and psychotherapeutic specialties in the practice of medicine, designed to identify and assist this category of patients, their number is not decreasing but increasing and the consequences of affective complications of BPD are becoming increasingly catastrophic.

Perhaps the roots of the problem the failure of suppression of BPD near the failure of the search for a new paradigm of psychiatry? The old paradigm of psychiatry stands on the Foundation of the formal-logical constructions. Without belittling the achievements of outstanding scientists working in this area, it is possible, however, to state that the result was created by science, have no objective method of study. All of this leads, ultimately, to arbitrary interpretations of the patient's condition, the reasons for his illness and tactics of further treatment. In fairness I must say that a practical science, and is currently unable to provide a sufficient amount of objective data that could be put in a basis of objective psychiatric diagnosis.

In this regard, constantly expresses the idea that the search for a new paradigm of psychiatry should be sought in connection with the pathology in the NGNB [4]. A chain of logical deductions about the relation of the alpha rhythm with entropy NGNB presented in previous publications of series of articles devoted to dispersion of the alpha rhythm [5].

Try these positions to address the issues of pathogenesis and diagnostics of PSR.

First of all, it should be understood that we mean by the term BPD. On this account, too, there are various interpretations from all these States to only one emotional personality disorders in ICD-10 (F60.3x) and DSM-5[3] to the expanded list of similar conditions.

I think that would be correct, if we follow the General features characteristic of BPD:

a) neurotic level, functional in nature and reversibility of the existing violations;

b) vegetative "maintenance", the presence of co morbid aesthetic, sleep and somatoform disorders;

c) connection of disease with the traumatic circumstances and personality-typological characteristics;

d) egodystonic (unacceptability to the "I" of the patient) of disease and the preservation of a critical attitude to the disease.

In borderline psychopathology are excluded:

a) Psychotic disorders (delusions, hallucinations); b) Growing progressive dementia;

c) Severe personality changes, disorders of thinking and behavior, egosyntonic (harmony, consonance for the "I" of the patient) symptoms characteristic of endogenous mental disorders [6].

\section{The Purpose of the Study}

To study the dispersion of violations of the alpha rhythm among patients suffering from BPD with the goal of determining the degree of entropy of the NGNB and places BPD in a number of other psychopathological conditions

\section{Materials and Methods}

Table 1: A list of patients classified as BPD.

\begin{tabular}{|c|c|}
\hline Nosological form & $\begin{array}{l}\text { Number } \\
\text { research }\end{array}$ \\
\hline F06.32 Organic depressive disorder & 15 \\
\hline F06.4 Organic anxiety disorder & 5 \\
\hline F06.5 Organic dissociative disorder & 5 \\
\hline F06.6 Organic emotionally labile [asthenic] disorder & 14 \\
\hline F06.7 Mild cognitive disorder & 34 \\
\hline $\begin{array}{l}\text { F06.8 Other specified mental disorders due to brain } \\
\text { damage and dysfunction and to physical disease }\end{array}$ & 58 \\
\hline $\begin{array}{l}\text { F06.9 Unspecified mental disorder due to brain damage } \\
\text { and dysfunction and to physical disease }\end{array}$ & 5 \\
\hline $\begin{array}{l}\text { F07 Personality and behavioral disorder due to } \\
\text { brain disease, damage and dysfunction }\end{array}$ & 262 \\
\hline F32.0 Mild depressive episode & 16 \\
\hline F32.1 Moderate depressive episode & 15 \\
\hline $\begin{array}{l}\text { F32.2 Severe depressive episode without psychotic } \\
\text { symptoms }\end{array}$ & 12 \\
\hline $\begin{array}{l}\text { F33.0 Recurrent depressive disorder, current episode } \\
\text { mild }\end{array}$ & 11 \\
\hline $\begin{array}{l}\text { F33.1 Recurrent depressive disorder, current episode } \\
\text { moderate }\end{array}$ & 13 \\
\hline $\begin{array}{l}\text { F33.2 Recurrent depressive disorder, current episode } \\
\text { severe without psychotic symptoms }\end{array}$ & 7 \\
\hline F34.0 Cyclothymia & 8 \\
\hline F34.1 Dysthymia & 6 \\
\hline F40 Phobic anxiety disorders & 5 \\
\hline F41 Other anxiety disorders & 4 \\
\hline F42 Obsessive - compulsive disorder & 2 \\
\hline F43 Reaction to severe stress, and adjustment disorders & 32 \\
\hline F44 Dissociative [conversion] disorders & 1 \\
\hline F45 Somatoform disorders & 11 \\
\hline F48.0 Neurasthenia & 11 \\
\hline F50 Eating disorders & 2 \\
\hline F51 Nonorganic sleep disorders & 0 \\
\hline F52.0 Lack or loss of sexual desire & 0 \\
\hline F60 Specific personality disorders & 584 \\
\hline Total & 1138 \\
\hline
\end{tabular}




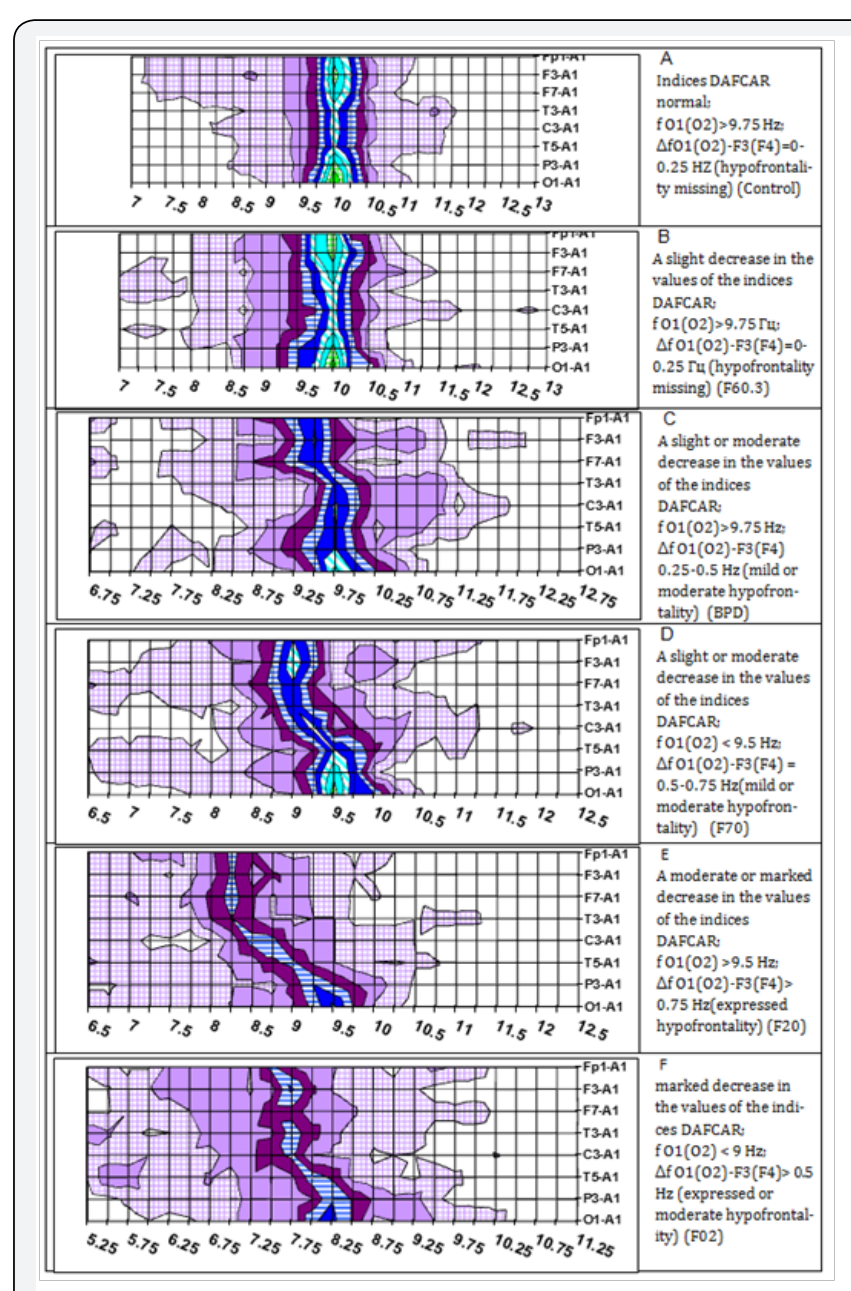

Figure 1: The comparative data of the indices of the DAFCAR and the dispersion cartogram of alpha-rhythm in various nosological forms of psychopathology.

In accordance with the stated signs of BPD, and according to available medical literature were outlined, the range of diseases in accordance with ICD-10, which can be attributed to this category of psychopathology (Table 1 ). The study involved men young and middle age $(24,4 \pm 1.1$ years, $C V \%=39 \%)$. As a control, studied 44 young men $(22.6 \pm 0.8$ years, $C V \%=26 \%)$, the commission of experts recognized mentally healthy. All subjects performed a standard EEG study with the imposition of electrodes on the international system "10-20\%" and an ear reference electrode. In addition, conducted a hyperventilation test according to a standard technique in the modification of Rosman s [7]. Analysis of variance of the alpha rhythm was conducted by the method of Rosman [8-10]. Data for comparison with other types of psychopathology are taken from studies carried out earlier [11-12]. Most evident are the results of analysis of variance for comparative maps of the alpha rhythm. Dynamics of changes depending on the index values, DAFCAR represented in the inscriptions near the base. It is easy to see that cartograms with BPD take an intermediate place between the lung disorders personal (which differ from the norm) and mild mental retardation - the mildest form of psychopathology (Figure 1). Quite interesting data obtained in the study of the results of hyperventilation samples (Figure 2) was observed a distinct increase, compared to the norm, the proportion of endogenous reactions.

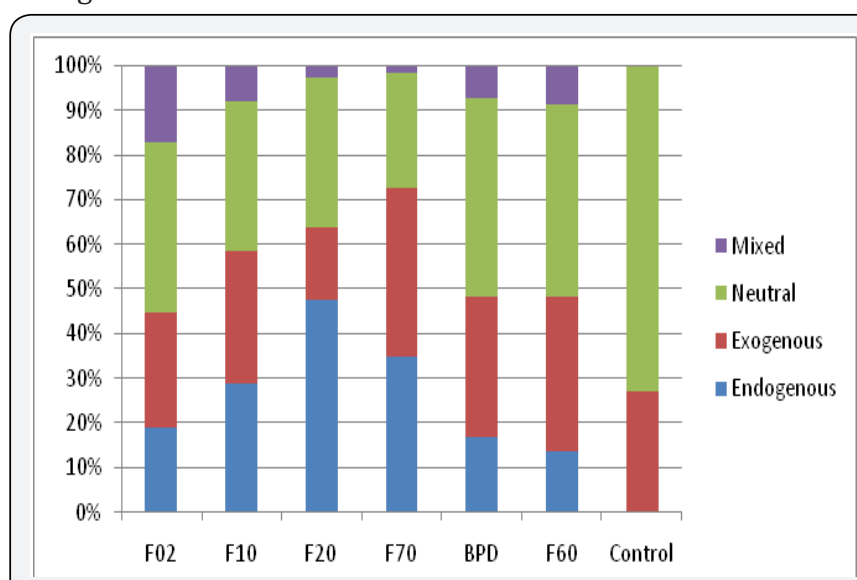

Figure 2: The Proportion of different response types during hyperventilation tests in various forms of mental illness.

This method of research seems very promising, as already mentioned in previous publications on this subject [7]. However, due to the fact that these studies started recently to fully explain them is difficult. Noteworthy, gradual increase in the proportion of endogenous reactions as weighting of psychopathology to schizophrenia but dementia and alcoholism are "in the field" exogenous processes, which confirms a predominantly "vascular" origins of the changes to the NGNB in these diseases.

\section{Discussion}

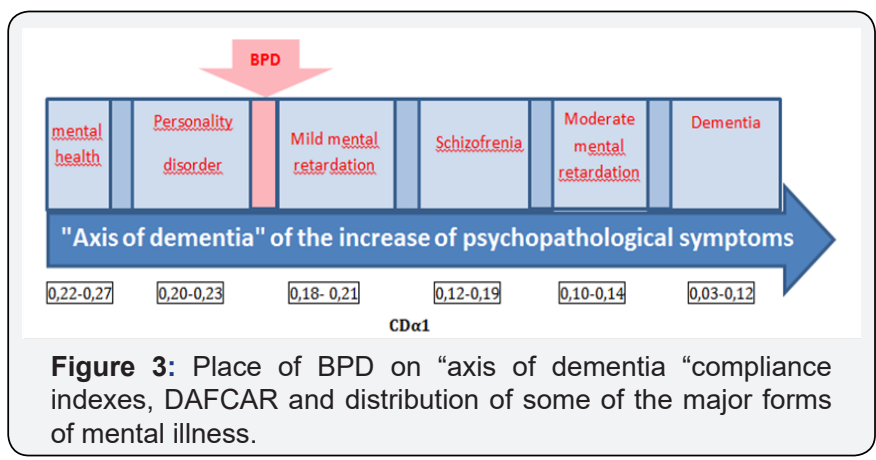

Of course, this study cannot claim the role of a comprehensive. However, it shows that there is a clear link between the degree of entropy of a neural network and the severity of the clinical manifestations of psychopathology. In this series of BPDis truly "intermediate" position (Figure 3). DAFCAR when BPD is less pronounced than in manifested forms of mental illness, but more than normal and milder forms of personality disorders (Tables 2 \& 3) and (Figure 1). Very interesting data from hyperventilation test. They show that in the pathogenesis of entropy NGNB major role is played by endogenous, possibly genetic, properties cytoarchitectonic of the brain. Naturally, Indices, DAFCAR do not point directly to the diagnosis, however, is quite useful in the differential diagnosis [5]. 
Table 2: Indices DAFCAR, obtained during examination of patients with BPD compared with normal and certain types of psychopathology (left hemisphere)

\begin{tabular}{|c|c|c|c|c|c|c|c|c|c|c|c|}
\hline \multirow[b]{2}{*}{ ICD-10 } & \multirow[b]{2}{*}{ Electrodes } & \multicolumn{2}{|c|}{ f 01(02), $\mathrm{Hz}$} & \multicolumn{2}{|c|}{ CD $\alpha$ l, c.u. } & \multicolumn{2}{|c|}{ CD $\alpha 2$, c.u. } & \multicolumn{2}{|c|}{$\begin{array}{c}\text { Asymmetry (ADA, } \\
\text { AH), c.u. }\end{array}$} & \multicolumn{2}{|c|}{$\begin{array}{l}\text { Kurtosis(IIDA, } \\
\text { IIH), c.u. }\end{array}$} \\
\hline & & $\begin{array}{c}E[X] \\
\text { Confidence } \\
\pm 95 \%\end{array}$ & CV\% & $\begin{array}{c}E[X] \\
\text { Confidence } \\
\pm 95 \%\end{array}$ & CV\% & $\begin{array}{c}E[X] \\
\text { Confidence } \\
\pm 95 \%\end{array}$ & CV\% & $\begin{array}{c}E[X] \\
\text { Confidence } \\
\pm 95 \%\end{array}$ & CV\% & $\begin{array}{c}\mathrm{E}[\mathrm{X}] \\
\text { Confidence } \\
\pm 95 \%\end{array}$ & CV\% \\
\hline \multirow{4}{*}{ F02.8 } & \multirow{2}{*}{ F3-A1 } & 7.7 & \multirow{2}{*}{20} & 0.115 & \multirow{2}{*}{54} & 0.371 & \multirow{2}{*}{40} & 1.338 & \multirow{2}{*}{59} & 1.988 & \multirow{2}{*}{148} \\
\hline & & $7.5-7.8$ & & $0.109-0.121$ & & $0.357-0.385$ & & $1.263-1.414$ & & $1.706-2.269$ & \\
\hline & \multirow{2}{*}{ 01-A1 } & 8.3 & \multirow{2}{*}{18} & 0.144 & \multirow{2}{*}{50} & 0.449 & \multirow{2}{*}{37} & 1.528 & \multirow{2}{*}{50} & 2.425 & \multirow{2}{*}{130} \\
\hline & & $8.2-8.5$ & & $0.137-0.151$ & & $0.434-0.465$ & & $1.454-1.601$ & & $2.123-2.728$ & \\
\hline \multirow{4}{*}{ F20. } & \multirow[b]{2}{*}{ F3-A1 } & 8.2 & \multirow[b]{2}{*}{21} & 0.112 & \multirow[b]{2}{*}{48} & 0.364 & \multirow[b]{2}{*}{34} & 1.215 & \multirow[b]{2}{*}{74} & 1.96 & \multirow[b]{2}{*}{164} \\
\hline & & 7.8-8.6 & & $0.1-0.124$ & & $0.336-0.392$ & & $1.009-1.421$ & & $1.224-2.696$ & \\
\hline & \multirow{2}{*}{ 01-A1 } & 9.5 & \multirow{2}{*}{11} & 0.155 & \multirow{2}{*}{43} & 0.484 & & 1.589 & & 2.761 & \\
\hline & & $9.2-9.7$ & & $0.14-0.17$ & & $0.453-0.516$ & 28 & $1.411-1.767$ & 49 & $2.045-3.476$ & 113 \\
\hline & ᄃ2 1 & 10.1 & 6 & 0.206 & 20 & 0.566 & 27 & 2.169 & 27 & 5.095 & 71 \\
\hline $560 ?$ & FJ-A1 & $10.0-10.3$ & 0 & $0.188-0.224$ & 39 & $0.537-0.595$ & $2 Z$ & $1.986-2.353$ & 31 & $4.222-5.967$ & 14 \\
\hline 500.00 & 0 & 10.2 & 5 & 0.249 & 21 & 0.679 & 10 & 2.339 & 30 & 5.539 & 65 \\
\hline & O1-A1 & $10.1-10.3$ & 5 & $0.23-0.269$ & 34 & $0.651-0.706$ & 18 & $2.189-2.489$ & 28 & $4.714-6.365$ & 65 \\
\hline & $F 2 \wedge 1$ & 8.9 & 15 & 0.17 & 55 & 0.48 & 27 & 1.8 & 52 & 3.874 & 106 \\
\hline F7009 & F3-A1 & $8.7-9.1$ & 15 & $0.155-0.185$ & 55 & $0.452-0.507$ & 37 & $1.65-1.95$ & 53 & $3.231-4.516$ & 106 \\
\hline F/0.09 & 0 & 9.5 & 7 & 0.221 & 1 & 0.614 & 5 & 2.144 & 26 & 4.854 & 6 \\
\hline & O1-A1 & 9.4-9.7 & 1 & $0.207-0.235$ & 41 & $0.59-0.639$ & 25 & $2.025-2.264$ & 36 & $4.276-5.432$ & 76 \\
\hline & $F_{2}{ }^{2}$ & 9.3 & 14 & 0.135 & 12 & 0.416 & 23 & 1.408 & 51 & 2.23 & 110 \\
\hline ל קחס & F3-A1 & $9.2-9.5$ & 14 & $0.129-0.141$ & 42 & $0.4-0.431$ & 33 & $1.324-1.492$ & 54 & $1.909-2.551$ & 140 \\
\hline & 0 & 9.7 & 19 & 0.18 & 1 & 0.526 & 21 & 1.781 & 1 & 3.335 & 101 \\
\hline & U1-A1 & 9.6-9.9 & 11 & $0.171-0.189$ & 44 & $0.506-0.545$ & 31 & $1.692-1.871$ & 44 & $2.96-3.709$ & 101 \\
\hline & $F^{2}+2$ & 10.1 & 6 & 0.192 & $36+2>$ & 0.563 & 22 & 2.256 & 28 & 5.366 & 56 \\
\hline$c$ & F3-A1 & $10.0-10.2$ & 6 & $0.178-0.205$ & 36 & $0.539-0.588$ & $2 Z$ & $2.136-2.376$ & 28 & $4.784-5.948$ & 56 \\
\hline Contror & 1 & 10.1 & 5 & 0.269 & 15 & 0.714 & 0 & 2.599 & 12 & 6.685 & 21 \\
\hline & -A1 & $10.0-10.2$ & 5 & $0.261-0.277$ & 15 & $0.7-0.728$ & 10 & $2.532-2.665$ & 13 & $6.283-7.087$ & 31 \\
\hline
\end{tabular}

Note: $C V(\%)=\sigma /(E[X])$

$\mathrm{CV}(\%)$ - the coefficient of variation

$\sigma-$ the standard deviation of a random variable;

$E[X]$ - Expectedvalue.

Table 3: Indices DAFCAR, obtained during examination of patients with BPD compared with normal and certain types of psychopathology (right emisphere).

\begin{tabular}{|c|c|c|c|c|c|c|c|c|c|c|c|}
\hline \multirow[b]{2}{*}{ МКБ-10 } & \multirow[b]{2}{*}{ Отведения } & \multicolumn{2}{|c|}{ f 01(02), $\mathrm{Hz}$} & \multicolumn{2}{|c|}{ CD $\alpha$ l, c.u. } & \multicolumn{2}{|c|}{ CD $\alpha 2$, c.u. } & \multicolumn{2}{|c|}{$\begin{array}{c}\text { Asymmetry (ADA, AH), } \\
\text { c.u. }\end{array}$} & \multicolumn{2}{|c|}{$\begin{array}{l}\text { Kurtosis(IIDA, IIH), } \\
\text { c.u. }\end{array}$} \\
\hline & & $\begin{array}{c}\mathrm{E}[\mathrm{X}] \\
\text { Confidence } \\
\pm 95 \%\end{array}$ & $\mathrm{CV} \%$ & $\begin{array}{c}\mathrm{E}[\mathrm{X}] \\
\text { Confidence } \\
\pm 95 \%\end{array}$ & CV\% & $\begin{array}{c}E[X] \\
\text { Confidence } \\
\pm 95 \%\end{array}$ & CV\% & $\begin{array}{c}E[X] \\
\text { Confidence } \\
\pm 95 \%\end{array}$ & $\mathrm{CV} \%$ & $\begin{array}{c}E[X] \\
\text { Confidence } \\
\pm 95 \%\end{array}$ & $\mathrm{CV} \%$ \\
\hline \multirow{4}{*}{ F02.8 } & \multirow[t]{2}{*}{ F4-A2 } & 7.8 & \multirow[t]{2}{*}{20} & 0.116 & \multirow[t]{2}{*}{53} & 0.375 & \multirow[t]{2}{*}{40} & 1.399 & \multirow[t]{2}{*}{59} & 2.215 & \multirow[t]{2}{*}{142} \\
\hline & & 7.6-7.9 & & $0.11-0.122$ & & $0.36-0.389$ & & $1.32-1.477$ & & $1.913-2.517$ & \\
\hline & \multirow{2}{*}{ O2-A2 } & 8.3 & \multirow{2}{*}{18} & 0.149 & \multirow{2}{*}{52} & 0.454 & \multirow{2}{*}{38} & 1.61 & \multirow{2}{*}{50} & 2.79 & \multirow{2}{*}{123} \\
\hline & & $8.1-8.4$ & & $0.141-0.156$ & & $0.437-0.47$ & & $1.533-1.688$ & & $2.461-3.119$ & \\
\hline
\end{tabular}




\section{Global Journal of Addiction \& Rehabilitation Medicine}

\begin{tabular}{|c|c|c|c|c|c|c|c|c|c|c|c|}
\hline \multirow{4}{*}{ F20.094 } & \multirow{2}{*}{$\mathrm{F} 4-\mathrm{A} 2$} & 8.2 & \multirow{2}{*}{22} & 0.109 & \multirow{2}{*}{48} & 0.35 & \multirow{2}{*}{36} & 1.288 & \multirow{2}{*}{77} & 2.401 & \multirow{2}{*}{165} \\
\hline & & 7.8-8.6 & & $0.097-0.121$ & & $0.321-0.379$ & & $1.062-1.513$ & & $1.494-3.307$ & \\
\hline & \multirow{2}{*}{ O2-A2 } & 9.5 & \multirow{2}{*}{11} & 0.16 & \multirow{2}{*}{43} & 0.496 & \multirow{2}{*}{27} & 1.637 & \multirow{2}{*}{48} & 2.867 & \multirow{2}{*}{114} \\
\hline & & $9.3-9.8$ & & $0.144-0.175$ & & $0.465-0.526$ & & $1.458-1.816$ & & $2.12-3.615$ & \\
\hline \multirow{4}{*}{ F60.30 } & \multirow{2}{*}{ F4-A2 } & 10.0 & \multirow{2}{*}{6} & 0.204 & \multirow{2}{*}{40} & 0.562 & \multirow{2}{*}{24} & 2.128 & \multirow{2}{*}{38} & 4.885 & \multirow{2}{*}{78} \\
\hline & & $9.9-10.2$ & & $0.185-0.222$ & & $0.531-0.592$ & & $1.944-2.312$ & & $4.009-5.761$ & \\
\hline & \multirow{2}{*}{ O2-A2 } & 10.1 & \multirow{2}{*}{6} & 0.266 & \multirow{2}{*}{33} & 0.704 & \multirow{2}{*}{18} & 2.422 & \multirow{2}{*}{28} & 6.008 & \multirow{2}{*}{59} \\
\hline & & $10.0-10.3$ & & $0.246-0.286$ & & $0.675-0.733$ & & $2.268-2.576$ & & $5.187-6.829$ & \\
\hline \multirow{4}{*}{ F70.09 } & \multirow{2}{*}{ F4-A2 } & 9.0 & \multirow{2}{*}{15} & 0.168 & \multirow{2}{*}{54} & 0.476 & \multirow{2}{*}{35} & 1.81 & \multirow{2}{*}{52} & 3.916 & \multirow{2}{*}{107} \\
\hline & & 8.8-9.2 & & $0.154-0.182$ & & $0.45-0.503$ & & $1.662-1.959$ & & $3.263-4.57$ & \\
\hline & 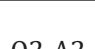 & 9.5 & 7 & 0.226 & 10 & 0.628 & 25 & 2.157 & 27 & 4.86 & 76 \\
\hline & $U L-A Z$ & $9.4-9.7$ & I & $0.212-0.24$ & 40 & $0.604-0.653$ & 25 & $2.033-2.281$ & 37 & $4.282-5.438$ & 16 \\
\hline & 540 & 9.3 & 12 & 0.138 & 4 & 0.417 & 32 & 1.445 & 55 & 2.358 & 140 \\
\hline D & P4-AZ & 9.1-9.4 & 13 & $0.131-0.144$ & 44 & $0.402-0.432$ & 32 & $1.356-1.534$ & 55 & $2.003-2.713$ & 140 \\
\hline BPD & 02-A2 & 9.7 & 11 & 0.188 & 44 & 0.541 & 31 & 1.85 & 43 & 3.612 & 98 \\
\hline & UL-AZ & $9.6-9.9$ & 11 & $0.178-0.197$ & 44 & $0.522-0.561$ & 31 & $1.757-1.943$ & 45 & $3.208-4.016$ & 90 \\
\hline & $\mathrm{F} 4-\mathrm{A} 2$ & 10.1 & 6 & 0.189 & 35 & 0.561 & 21 & 2.193 & 29 & 5.022 & 62 \\
\hline Control & $\mathrm{F} 4-\mathrm{AZ}$ & $10.0-10.2$ & 6 & $0.176-0.202$ & 35 & $0.538-0.583$ & 21 & $2.071-2.315$ & 29 & 4.417-5.627 & 62 \\
\hline & $0 ?+2>$ & 10.1 & 5 & 0.271 & 20 & 0.724 & 12 & 2.579 & 16 & 6.51 & 26 \\
\hline & $\mathrm{UL}-\mathrm{A} Z$ & $10.0-10.2$ & 5 & $0.261-0.282$ & 20 & $0.706-0.742$ & 13 & $2.499-2.659$ & 16 & $6.058-6.962$ & 36 \\
\hline
\end{tabular}

Special value of these studies for prevention of social excesses on the part of patients with BPD, especially aggressive and auto aggressive actions, Moreover, the data obtained from the patients; do not depend on his will, nor the level of education, religious and cultural differences. We get "clean" information about the functional state of the brain underlying the deviant behavior. It is well known that prevention of deviant behavior, including addictive behavior, as follows:

i. Preventing physical, psychological or socio-cultural conflicts of individuals and groups at risk;

ii. Preservation, maintenance and protection of normal living standards and health of people;

iii. Assist them in achieving their goals and discovering their inner potentials.

All these goals cannot be achieved unless they secured a certain level of mental health, which is based on psychophysiological processes, caused by the entropy of NGNB.

Simply put, in order to overcome the harmful addiction and deviant tendencies, one must possess certain volitional and intellectual abilities that are not possible with the destruction of the NGNB. Also important is the use of data, DAFCAR in the examination of the decreed contingents of people receiving access to weapons, vehicles, carrying out work associated with increased risk for the population and which places high emotional demands on the candidate. These data can be the basis for screening in the work of expert committees. Dynamic data tracking, DAFCAR in the treatment process will allow you to monitor its effectiveness and to contribute to the search for new techniques, implementing accelerated dynamic monitoring in real time, not on the results of the course of therapy.

\section{Conclusion}

i. $\quad B P D$, being the initial stage of mental illness are the root of many social problems

ii. In neurophysiologic basis of BPD are the processes of entropy NGNB

iii. Marker in the diagnosis of BPD there may be indexes DAFCAR

iv. Application of research methods, DAFCAR can become a new step in the study of psycho-pathology and prevention of deviant behavior: addictive diseases, aggression against others and auto aggression, the prevention of accidents at the industrial enterprises and transport.

\section{References}

1. Aviram RB, Hellerstein DJ, Gerson J, Stanley B (2004) Adapting supportive psychotherapy for individuals with Borderline personality disorder who self-injure or attempt suicide. J Psychiatr Pract 10(3): 145-55.

2. Binks CA, Fenton M, McCarthy L, Lee T, Adams CE, et al. (2006) Psychological therapies for people with borderline personality disorder. Cochrane database of systematic reviews (Online) (1): CD005652.

3. Diagnostic and Statistical Manual of Mental Disorders, $5^{\text {th }}$ edn (DSM-5) - Arlington, VA, 2013. Volume 5. 
4. Sanislow Charles A (2016) Updating the Research Domain Criteria. World Psychiatry 15(3): 222-223.

5. Rosman S (2017) The Theoretical Foundations of Dispersion of Amplitude-Frequency Characteristics of the Alpha Rhythm of the EEG. Glob J Add \& Rehab Med 2(3).

6. Gunderson JG MD (2006) Borderline Personality DisorderPsychotherapies. American Medical Network 166(5): 530-539.

7. Rosman S (2017) The Use of Analysis of Variance of the Alpha Rhythm of the EEG in the Study of the Pathogenesis of Alcoholism and the Causes of Alcoholic Deliria. Glob J Add \& Rehab Med 2(1): 555580.

8. Rosman SV (2013) Diagnostic capabilities of dispersion mapping the alpha rhythm of the electroencephalogram. Mental health 6: 64-69.
9. Rosman SV (2013) Opportunities of the dispersive mapping of the alpha rhythm of electroencephalogram in diagnostics of schizophrenia. Psychiatry 2: 32-37.

10. Rosman SV, Shpak LV (2013) New approaches to the assessment of polymorphism of the alpha rhythm of the electroencephalogram with mental illness. Mental health (2): 39-44.

11. Maximova NE, Rosman SV, Shpak LV, Zabodaev SV (2016) Possibilities of use of dispersion of an alpha rhythm for screening verification of mental diseases. Mental health 1: 16-25.

12. Goldberg E, Bilder RM, Hughes JE, Antin SP, Matti S (1989) A reticulo-frontal disconnection syndrome. Cortex 25(4): 687-695.

\section{Your next submission with Juniper Publishers will reach you the below assets}

- Quality Editorial service

- Swift Peer Review

- Reprints availability

- E-prints Service

- Manuscript Podcast for convenient understanding

- Global attainment for your research

- Manuscript accessibility in different formats ( Pdf, E-pub, Full Text, Audio)

- Unceasing customer service

Track the below URL for one-step submission https://juniperpublishers.com/online-submission.php 